\title{
COMUNICAÇÃO
}

\section{PRODUÇÃO E QUALIDADE DE BOTÕES DE ROSA CV.VEGA CULTIVADOS SOB PLÁSTICOS DE COBERTURA COM DIFERENTES ANOS DE USO ${ }^{1}$}

\author{
Production and quality of floral buds for rose cv. Vega (Rosa SP.) cultivated under \\ plastic with different years of use
}

\author{
José Luis Martins², Maria Angela Fagnani ${ }^{3}$, Sônia Maria D'stefano Piedade ${ }^{4}$
}

\begin{abstract}
RESUMO
Objetivou-se, neste trabalho, avaliar a produção e qualidade de botões de rosa cultivar Vega ( Rosa sp. ), cultivada sob cobertura plástica com diferentes anos de uso. Para tanto foram selecionados 15 vãos de estufas com plásticos colocados em 1998, 1999, 2002, 2003, e testemunha (sem uso anterior), com três repetições, avaliados por duas maneiras: na primeira os frutos foram colhidos através de uma poda (como procedimento do cultivo comercial); na segunda foi realizada uma poda rasa em uma área de $1 \mathrm{~m}^{2}$ para poder acompanhar o crescimento da haste floral desde o início da formação até a fase de botão floral. No primeiro caso foram realizadas 4 coletas ao longo do período do experimento, nas quais foram coletadas 4 hastes florais por tratamento, totalizando 60 flores por data de coleta. No segundo caso foi avaliado o aparecimento dos botões florais dos novos brotos em quatro datas até a formação das hastes florais comerciais, e então coletadas 13 hastes florais por tratamento. Não houve diferença estatística entre os anos de uso dos plásticos de 1998, 1999, 2002 e 2003 nas variáveis: comprimento, diâmetro e comprimento dos botões florais, massa fresca e seca das pétalas, para as condições e cultivar analisados. Com isso o produtor ganha um período maior de utilização do plástico gerando um custo menor, sem perdas na produção.
\end{abstract}

Termos para indexação: Floricultura, produção de rosa, cultivo protegido, cobertura plástica, Rosa sp.

\begin{abstract}
The aim of this study was to evaluate the production and quality of floral buds of rose cv. Vega (Rosa sp.) cultivated underneath a plastic film used as greenhouse covering, with different years of use. In order to evaluate the bud production and quality, 15 greenhouse gaps with plastic covering dating from 1998, 1999, 2002, 2003, were selected; and the control covering (never used before) with three replications each. Two types of evaluation were made for this analysis: the first one, the fruits were harvested by means of pruning (as the commercial use standard procedure); in the second evaluation a clear cut pruning was conducted in an area of $1 \mathrm{~m}^{2}$ with the purpose of determining the development of the flower buds from the pruning to the commercial flower stalk. On the first evaluation, 4 harvestings were conducted during the entire experiment period, in which 4 flower stalks per treatments were collected, totaling 60 flowers per collecting date. On the second evaluation, floral buds emerging on new shoots were determined in four different dates until commercial flower stalks complete formation was achieved, then 13 flower stalks per treatment were collected. There was no statistical difference among the plastic films with different years of use regarding stalk length and diameter, flower bud diameter and length, dry and fresh petal mass under the analyzed conditions and cultivars, translating into a larger period of plastic covering use without loss in the production at a low production cost.
\end{abstract}

Index terms: Florist; flower rose production; greenhouse, plastic covering, Rosa sp.

\section{(Recebido em 26 de março de 2007 e aprovado em 6 de agosto de 2007)}

Os floricultores estão constantemente pressionados pela busca de novas tecnologias devido à alta competitividade e rentabilidade do setor, incluindo o cultivo em casas de vegetação.

Uma vez que o custo do plástico de cobertura e a mão-de-obra no seu manejo (limpeza, colocação, pintura com tinta branca na primavera e a lavagem da pintura no outono) estão entre os maiores gastos na cultura da roseira (Rosa sp.), um maior período de uso do plástico traduz-se em menores gastos ao produtor. No Brasil, o principal plástico usado na agricultura é o polietileno de baixa densidade (PEBD), graças à boa qualidade e versatilidade

\footnotetext{
'Parte da Tese apresentada à Faculdade de Engenharia Agrícola da Universidade Estadual de Campinas, pelo primeiro autor, para obtenção do grau de Doutor em Engenharia Agrícola na área de Água e Solos.

2Engenheiro Agrônomo, Doutor - Faculdade de Engenharia Agrícola/FEAGRI - Universidade Estadual de Campinas/UNICAMP - R: Zeferino Vaz s/n Bairro Barão Geraldo - Cx. P.6011 - 13083-970 - Campinas,SP - martinsjl@yahoo.com.br

${ }^{3}$ Engenheira Agrônoma, Doutor - Faculdade de Engenharia Agrícola/FEAGRI - Universidade Estadual de Campinas/UNICAMP - R: Zeferino Vaz s/n Bairro Barão Geraldo - Cx. P. 6011 - 13083-970 - Campinas,MG - angela@feagri.unicamp.br

"Engenheira Agrônoma, Doutor - Escola Superior de Agricultura "Luiz de Queiróz"/ESALQ - Universidade de São Paulo/USP - Av. Pádua Dias n 11 Bairro São Judas - Cx.P. 09 - 13418-900 - Piracicaba,SP - soniamsp@esalq.usp.br
} 
do produto final e ao preço mais acessível em comparação aos demais. O PEBD começou a ser pesquisado e difundido no Brasil a partir de 1970 e é utilizado na maioria dos cultivos sob casa de vegetação. A razão de tal preferência é explicada pela versatilidade e excelente qualidade dos produtos finais elaborados com o mesmo, e pelo baixo custo, se comparado aos demais agroplásticos. Tanto trabalhos em túneis altos (CUNHA et al., 2001), como em estufas (COSTA, 2001; FURLAN \& FOLEGATTI, 2002; MORANDI, 1997; PEREIRA, 2002; ROCHA, 2002; RODRIGUES, 1999), atestaram o bom desempenho tanto do cultivo protegido como do plástico de cobertura empregado. Objetivou-se, neste trabalho, avaliar os aspectos produtivos de plantas de roseira da cultivar Veja, cultivadas em casas de vegetação, cobertas com filme plástico com diferentes anos de uso, para comparar o tempo adequado de uso dos plásticos.

O experimento foi realizado no período de 28/01/ 2004 a 12/04/2004 em uma propriedade comercial (Sítio Lagoa Dourada), na região da Serra do Caracol na sua porção norte, no município de Andradas, MG, a uma altitude de $1360 \mathrm{~m}$, com as coordenadas geográficas de $22^{\circ}$ 0050 Lat. S e $46^{\circ} 3202$ Long. W. Pela classificação de Köppen, é o Cwb, isso é, clima mesotérmico, caracterizado por verões brandos e úmidos. A precipitação média anual varia de 1500 a $1800 \mathrm{~mm}$. O período seco é curto e dura de 2 a 3 meses, coincidindo com os meses frios (junho-julhoagosto). A temperatura média é de $20^{\circ} \mathrm{C}$. A amplitude térmica anual (diferença entre a média do mês mais quente e a média do mês mais frio) varia de 5 a $7^{\circ} \mathrm{C}$. No inverno são registradas temperaturas mínimas absolutas inferiores a $0^{\circ} \mathrm{C}$ e o fenômeno das geadas é comum durante os dias mais frios.

As estufas, com padrão de $6,4 \mathrm{~m}$ de largura por 49,5m de comprimento, com pé direito de 3,50m (altura da calha), com cobertura em arco, estão localizadas no sentido leste-oeste em terreno levemente inclinado nessa mesma direção.

A rosa de corte é a principal cultura da propriedade com aproximadamente 3,5 hectares de estufas cultivadas. Como cultivares novas tem-se Versília, Greta e Carol, e como cultivar mais antiga tem-se a Vega. Esta cultivar apresenta uma coloração vermelha intensa com muitas pétalas, inodora e boa formação de massa verde. $\mathrm{Na}$ propriedade, as primeiras roseiras da cultivar Vega foram formadas em 1996, sucessivamente em 1997 e as últimas em 1998. Devido à grande área plantada, esta cultivar foi selecionada para analisar as características de produção na avaliação do efeito do tempo de uso da cobertura plástica sobre a cultura implantada.

Os meses mais quentes foram escolhidos para as coletas de dados em decorrência das maiores temperaturas no interior das estufas e também por serem os meses de maior produção. Definiu-se um período de coleta de 60 dias por ser este o tempo aproximado para a produção de um botão floral nessa época do ano, da poda da roseira até a produção da haste comercial.

No intuito de melhor avaliar o efeito do filme plástico de cobertura sobre a cultura da rosa foram analisados os plásticos instalados em 1998, 1999, 2002, 2003 e testemunha (um plástico sem uso anterior), caracterizando 5 tratamentos, correspondendo cada tratamento a cada ano de uso. Para as análises da produção foram realizadas duas formas de colheita. Na primeira foram coletadas flores de cultivo comercial em 4 datas (01/03/2004, 17/03/2004, 26/ 03/2004 e 05/04/2004), tendo sido coletadas 12 flores por tratamento, (5 tratamentos x 3 vãos de estufas x 4 flores por vão), totalizando 60 hastes florais por coleta. $\mathrm{Na}$ segunda foi realizada previamente uma poda rasa em 05/ 02/2004 deixando uma área de $1 \mathrm{~m}^{2}$ de cada vão das estufas selecionadas para o experimento, com o intuito de tornar possível acompanhar e monitorar o surgimento e crescimento dos novos brotos. As observações para esse acompanhamento foram realizadas nas datas 20 / 02/2004, 07/03/2004, 26/03/2004 e no período de 28/03 a 05/04/2004 ocorrendo o corte das mesmas no dia 05/04/ 04. Para essa segunda etapa, da poda rasa da haste até a formação da haste floral comercial foram coletadas 13 flores por tratamento ( 4 tratamentos, totalizando 52 hastes florais), no dia 05/04/04. Foram analisadas as seguintes características: comprimento e diâmetro basal da haste; diâmetro e comprimento dos botões florais; massa fresca e seca das pétalas. Essas medidas foram realizadas no Departamento de Pós-Colheita da Faculdade de Engenharia Agrícola da UNICAMP, Campinas SP.

Para a primeira etapa de avaliação foram analisadas as variáveis referentes às coletas realizadas nas quatro datas 01/03/2004; 17/03/2004; 26/03/2004 e 05/04/2004. Para a segunda, proveniente da área previamente cortada para observação do desenvolvimento das hastes e botões florais, foram avaliadas as variáveis referentes à coleta da data de 05/04/04 (final do período de crescimento da segunda etapa). Assim, em todas as tabelas a última coluna à direita refere-se aos dados da segunda etapa, que foi analisada junto à primeira etapa, uma vez que se tratam das mesmas variáveis. 


\section{a) Comprimento da haste floral}

Para o comprimento da haste, nas várias datas da primeira etapa, os valores médios estão representados pela Figura 1 e Tabela 1. Nota-se que não houve estatisticamente diferença, a $0,5 \%$ de significância para os tratamentos dentro das várias datas de coleta. No entanto, houve redução significativa nas médias de todos os tratamentos estudados na coleta do dia 17/03/2004, em decorrência de uma infecção de oídio.

Um dos principais parâmetros para avaliar a qualidade da haste floral é o comprimento da haste, sendo valorizadas as mais compridas, com o comprimento mínimo de $60 \mathrm{~cm}$, em razão de uma vida útil maior. A troca dos plásticos velhos por plásticos novos ( 2 anos ou menos de uso) não mostrou ser relevante para esta cultivar, pois não houve diferença entre o comprimento das hastes, contrariando a premissa entre os produtores que plásticos novos resultam em hastes florais com melhor qualidade. Casarini (2004), em estudo com fertirrigação em rosas, encontrou um comprimento médio de $50,51 \mathrm{~cm}$, em 60 dias de produção.

$\mathrm{Na}$ última coluna à direita são apresentados os valores de flores colhidas na área previamente cortada rasa para observação do desenvolvimento das hastes e botões florais. Embora o objetivo do trabalho não seja a comparação entre os dois procedimentos, mas sim entre tratamentos de plásticos de anos diferentes, foi observada uma semelhança nos resultados.

\section{b) Comprimento do botão floral}

Os valores médios para o comprimento do botão floral, nas datas de coleta, são apresentados na Figura 2 e Tabela 2. Esses valores estão de acordo com o valor médio obtido por Casarini (2004), sendo 48,57 $\mathrm{mm}$. Não houve, estatisticamente, diferença entre os tratamentos e, novamente a coleta do dia 17/03/04 apresentou valores médios abaixo das demais datas de coleta em decorrência do ataque de oídio. Uma boa formação do botão floral está na proporção harmoniosa

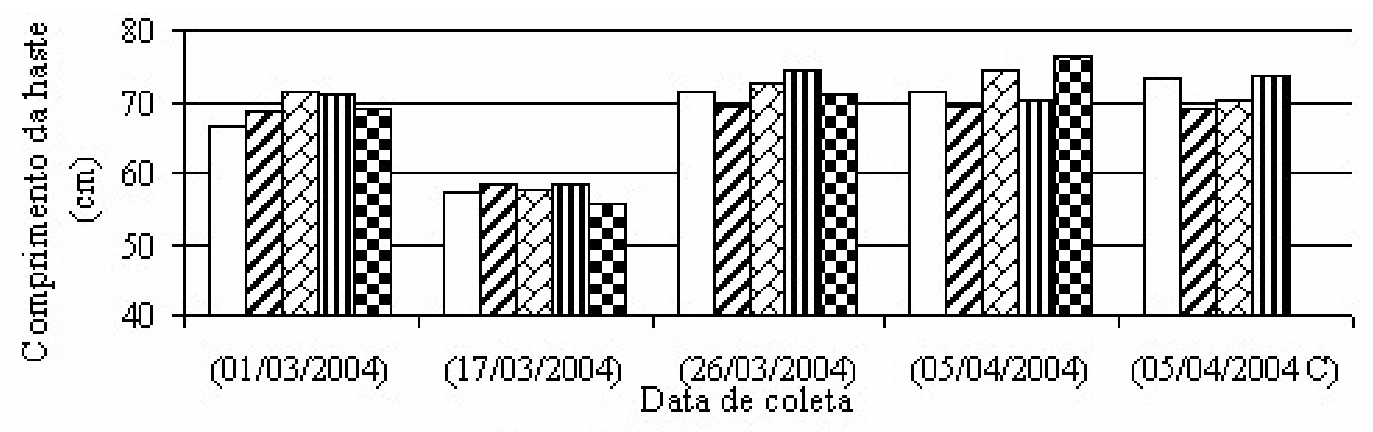

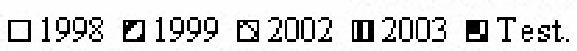

Figura 1 - Valores médios, nas datas de coleta, para o comprimento da haste $(\mathrm{cm})$, nos vários tratamentos estudados. A última coluna à direita refere-se aos dados das plantas que foram podadas no início do tratamento.

Tabela 1 - Valores médios para o comprimento da haste $(\mathrm{cm})$, nas datas de coleta e nos vários tratamentos estudados.

\begin{tabular}{cccccc}
\hline Tratamentos & $1 / 3 / 2004$ & $17 / 3 / 2004$ & $26 / 3 / 2004$ & $5 / 4 / 2004$ & $05 / 04 / 04 \mathrm{C}$ \\
\hline 1998 & $66,7 \mathrm{a}$ & $57,4 \mathrm{a}$ & $71,3 \mathrm{a}$ & $71,4 \mathrm{a}$ & $71,9^{\mathrm{a}}$ \\
1999 & $68,7 \mathrm{a}$ & $58,3 \mathrm{a}$ & $69,6 \mathrm{a}$ & $69,3 \mathrm{a}$ & $71,4^{\mathrm{a}}$ \\
2002 & $71,4 \mathrm{a}$ & $57,6 \mathrm{a}$ & $72,5 \mathrm{a}$ & $74,4 \mathrm{a}$ & $71,5^{\mathrm{a}}$ \\
2003 & $70,9 \mathrm{a}$ & $58,6 \mathrm{a}$ & $74,5 \mathrm{a}$ & $70,2 \mathrm{a}$ & $72,1^{\mathrm{a}}$ \\
Test. & $69,0 \mathrm{a}$ & $55,6 \mathrm{a}$ & $71,0 \mathrm{a}$ & $76,6 \mathrm{a}$ & \\
& & & & & 6,53 \\
DMS & 6,05 & 4,25 & 7,57 & 8,57 & 9,42 \\
C.V. $(\%)$ & 7,57 & 6,42 & 9,15 & 10,27 & 71,7 \\
Média Geral & 69,3 & 57,5 & 71,8 & 72,4 & 1,704 \\
I.C. $(1-0,05)$ & 1,383 & 0,961 & 1,696 & 1,988 & \\
\hline
\end{tabular}

Letras diferentes em uma mesma coluna indicam diferença significativa a 0,5 de significância, para o teste de Tukey. 


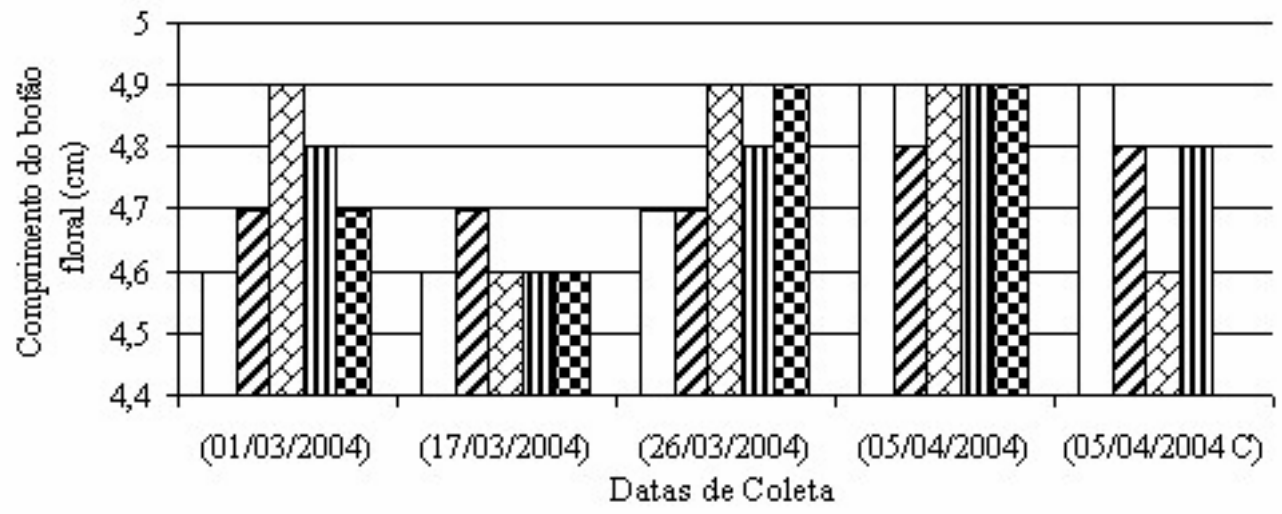

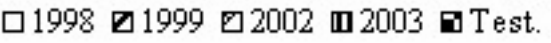

Figura 2 - Valores médios, nas datas de coleta, para o comprimento do botão floral (cm) nos diversos tratamentos estudados. A última coluna à direita refere-se aos dados das plantas que foram podadas no início do tratamento.

Tabela 2 - Valores médios do comprimento do botão floral $(\mathrm{cm})$, nas datas de coleta e nos diversos tratamentos estudados.

\begin{tabular}{cccccc}
\hline Tratamentos & $1 / 3 / 2004$ & $17 / 3 / 2004$ & $26 / 3 / 2004$ & $5 / 4 / 2004$ & $05 / 04 / 04 \mathrm{C}$ \\
\hline 1998 & $4,6 \mathrm{a}$ & $4,6 \mathrm{a}$ & $4,7 \mathrm{a}$ & $4,9 \mathrm{a}$ & $4,9 \mathrm{a}$ \\
1999 & $4,7 \mathrm{a}$ & $4,7 \mathrm{a}$ & $4,7 \mathrm{a}$ & $4,8 \mathrm{a}$ & $4,8 \mathrm{a}$ \\
2002 & $4,9 \mathrm{a}$ & $4,6 \mathrm{a}$ & $4,9 \mathrm{a}$ & $4,9 \mathrm{a}$ & $4,7 \mathrm{a}$ \\
2003 & $4,8 \mathrm{a}$ & $4,6 \mathrm{a}$ & $4,8 \mathrm{a}$ & $4,9 \mathrm{a}$ & $4,9 \mathrm{a}$ \\
Test. & $4,7 \mathrm{a}$ & $4,6 \mathrm{a}$ & $4,9 \mathrm{a}$ & $4,9 \mathrm{a}$ & \\
& & & & \\
DMS & 0,331 & 0,397 & 0,339 & 0,324 & 0,3 \\
C.V. $(\%)$ & 6 & 7,44 & 6,07 & 5,72 & 6,4 \\
Média Geral & 4,79 & 4,64 & 4,84 & 4,92 & 4,87 \\
I.C. $(1-0,05)$ & 0,076 & 0,087 & 0,077 & 0,073 & 0,08 \\
\hline
\end{tabular}

Letras diferentes em uma mesma coluna indicam diferença significativa a 0,5 de significância para o teste de Tukey.

do comprimento com o diâmetro evidenciando um produto de qualidade. Todos os comprimentos dos botões florais analisados nesse experimento estão dentro da faixa exigida pelo mercado.

Bredmose (1997) mostra a influência do aumento da radiação para a não formação de botões cegos, o que é confirmado neste experimento, evidenciando a necessidade da radiação fotossinteticamente ativa para o pleno desenvolvimento dos botões. Como não houve diferença entre os anos de uso, significa que os plásticos continuaram a deixar passar a radiação.

Moe (1971) concluiu que a temperatura constante por mais de 21 dias favorece a manutenção dos botões florais( não ocorrência de abortos) indicando a importância da manutenção da temperatura interna estável proporcionada pela cobertura plástica.

\section{c) Diâmetro do botão floral}

Os valores médios para o diâmetro do botão floral, para a coleta de 05/04/04, são apresentados na Figura 3 e Tabela 3. Houve diferença estatística entre os tratamentos apenas nas datas de coleta do dia 05/04/04 (da primeira etapa), onde o tratamento testemunha e 2003 foram inferiores ao de 1999 e não diferiram entre si. Os tratamentos 1998 e 2002 não diferem da testemunha 2003 como do tratamento 1999. Novamente, a coleta de 17/03/04 


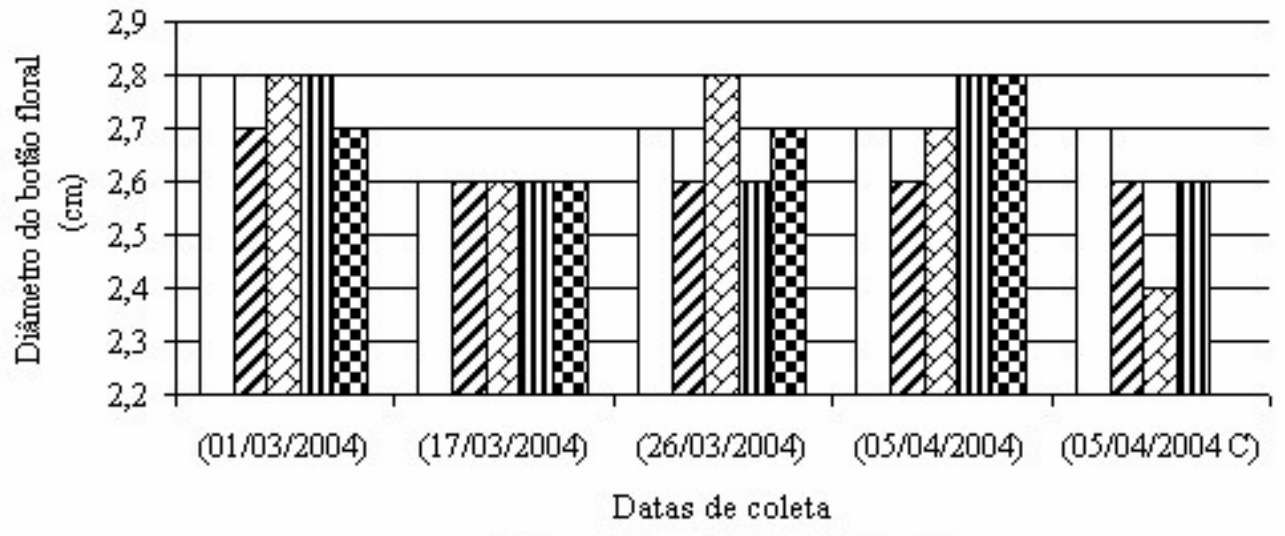

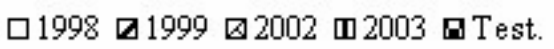

Figura 3 - Valores médios, nas datas de coleta, para o diâmetro do botão floral $(\mathrm{cm})$ nos diversos tratamentos estudados. A última coluna à direita refere-se aos dados das plantas que foram podadas no início do tratamento.

Tabela 3 - Valores médios do diâmetro do botão floral $(\mathrm{cm})$, para as diversas datas e nos diversos tratamentos estudados.

\begin{tabular}{cccccc}
\hline Tratamentos & $1 / 3 / 2004$ & $17 / 3 / 2004$ & $26 / 3 / 2004$ & $5 / 4 / 2004$ & $05 / 04 / 04 \mathrm{C}$ \\
\hline 1998 & $2,8 \mathrm{a}$ & $2,6^{\mathrm{a}}$ & $2,7 \mathrm{a}$ & $2,7 \mathrm{ab}$ & $2,7 \mathrm{a}$ \\
1999 & $2,7 \mathrm{a}$ & $2,6^{\mathrm{a}}$ & $2,6 \mathrm{a}$ & $2,6 \mathrm{~b}$ & $2,7 \mathrm{a}$ \\
2002 & $2,8 \mathrm{a}$ & $2,6^{\mathrm{a}}$ & $2,8 \mathrm{a}$ & $2,7 \mathrm{ab}$ & $2,6 \mathrm{a}$ \\
2003 & $2,8 \mathrm{a}$ & $2,6^{\mathrm{a}}$ & $2,6 \mathrm{a}$ & $2,8 \mathrm{a}$ & $2,6 \mathrm{a}$ \\
Test. & $2,7 \mathrm{a}$ & $2,6^{\mathrm{a}}$ & $2,7 \mathrm{a}$ & $2,8 \mathrm{a}$ & \\
& & & & & \\
DMS & 0,239 & 0,184 & 0,228 & 0,206 & 0,15 \\
C.V. (\%) & 7,45 & 6,04 & 7,24 & 6,41 & 5,76 \\
Média Geral & 2,78 & 2,65 & 2,73 & 2,78 & 2,7 \\
I.C. (1- 0,05) & 0,053 & 0,04 & 0,052 & 0,051 & 0,041 \\
\hline
\end{tabular}

Letras diferentes em uma mesma coluna indicam diferença significativa a 0,5 de significância, para o teste de Tukey.

apresentou a menor média entre os dias de coleta (oídio) . Também para a segunda etapa de 05/04/04, os tratamentos 1998 e 1999 foram iguais entre si e superiores ao tratamento 2003. Essas diferenças estatísticas não caracterizaram uma tendência de um melhor tratamento, mas sim a interferência do manejo principalmente em função do surgimento de doenças como o oídio e míldio em vãos pontuais das estufas, padrão evidenciado pelas coletas das datas de 01/03/04, 17/03/04 e 26/03/05 onde não houve diferença entre as coberturas de diferentes anos de uso, para o diâmetro dos botões florais.
Os valores dos diâmetros apresentados estão acima dos valores encontrados para Casarini (2004), cuja média geral foi de $2.2 \mathrm{~cm}$.

\section{d) Massa fresca e seca das pétalas}

Valores médios da massa fresca das pétalas do botão floral estão apresentados na Figura 4 e na Tabela 4. No dia 26/03/04, os tratamentos 1998, 1999 e a testemunha não diferiram do tratamento 2002 e de 2003 , entretanto, os tratamentos de 2002 e 2003 diferiram estatisticamente entre si. No dia 05/04/04, os tratamentos 2002, 2003, testemunha 


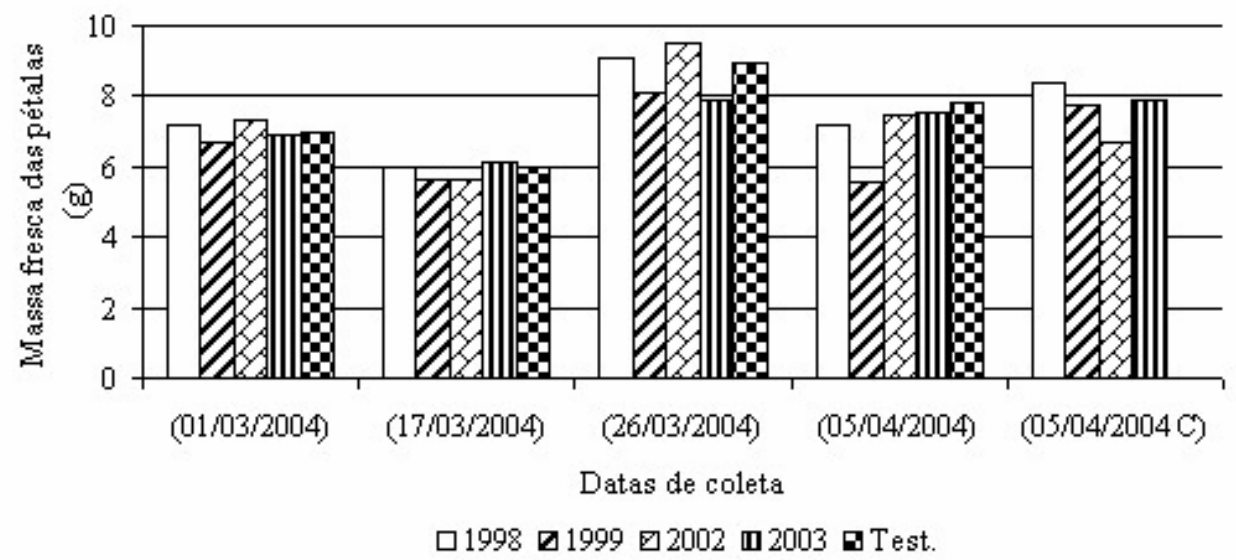

Figura 4 - Valores médios, nas datas de coleta, para a massa fresca das pétalas (g) nos diversos tratamentos estudados. A última coluna à direita refere-se aos dados das plantas que foram podadas no início do tratamento.

Tabela 4 - Valores médios de massa fresca das pétalas do botão floral (g), nas diversas datas de coleta e nos diversos tratamentos estudados.

\begin{tabular}{cccccc}
\hline Tratamentos & $1 / 3 / 2004$ & $17 / 3 / 2004$ & $26 / 3 / 2004$ & $5 / 4 / 2004$ & $05 / 04 / 04$ Corte \\
\hline 1998 & $7,153 \mathrm{a}$ & $6,020 \mathrm{a}$ & $9,109 \mathrm{ab}$ & $7,163 \mathrm{ab}$ & $8,396 \mathrm{a}$ \\
1999 & $6,687 \mathrm{a}$ & $5,621 \mathrm{a}$ & $8,123 \mathrm{ab}$ & $5,538 \mathrm{~b}$ & $7,716 \mathrm{ab}$ \\
2002 & $7,306 \mathrm{a}$ & $5,636 \mathrm{a}$ & $9,506 \mathrm{a}$ & $7,442 \mathrm{a}$ & $6,673 \mathrm{~b}$ \\
2003 & $6,882 \mathrm{a}$ & $6,128 \mathrm{a}$ & $7,867 \mathrm{~b}$ & $7,549 \mathrm{a}$ & $7,787 \mathrm{ab}$ \\
Test. & $6,996 \mathrm{a}$ & $5,969 \mathrm{a}$ & $8,935 \mathrm{ab}$ & $7,805 \mathrm{a}$ & \\
& & & & & \\
DMS & 1,66 & 1,416 & 1,631 & 1,869 & 1,67 \\
C.V. $(\%)$ & 20,6 & 20,93 & 16,27 & 22,86 & 23,1 \\
Média Geral & 7,005 & 5,875 & 8,708 & 7,099 & 7,504 \\
I.C. $(1-0,05)$ & 0,365 & 0,312 & 0,388 & 0,456 & 0,468 \\
\hline
\end{tabular}

Letras diferentes em uma mesma coluna indicam diferença significativa a 0,5 de significância, para o teste de Tukey.

e 1998 não diferiram estatisticamente entre si, entretanto diferiram do tratamento 1999.

Os valores aqui apresentados são corroborados por Casarini (2004) que encontrou valores médios totais de 7.85 g para massa fresca das pétalas. Na coleta de 17/03/2004, os valores estão abaixo, devido à infecção por oídio.

Valores médios da massa seca das pétalas do botão floral, nas diversas datas de coleta, estão apresentados na Figura 5 e na Tabela 5 e se correlacionam com o ítem massa fresca das pétalas do qual derivam. Essas diferenças estatísticas não caracterizaram uma tendência de um melhor tratamento, refletindo, no entanto o aparecimento de doenças (oídio e míldio), em diferentes pontos nas estufas estudadas. Os valores encontrados apresentam-se acima dos valores citados por Casarini (2004) que encontrou valor médio de massa seca de $1,25 \mathrm{~g}$.

Os diferentes anos de uso do plástico não interferiram nos aspectos acima mencionados de produção, mantendo o produto em condições normais de comércio indiferente do tempo de uso dos plásticos nas casas de vegetação. Com isso o produtor mantém a qualidade do produto e ganha um período maior de utilização do plástico, gerando um custo menor. 


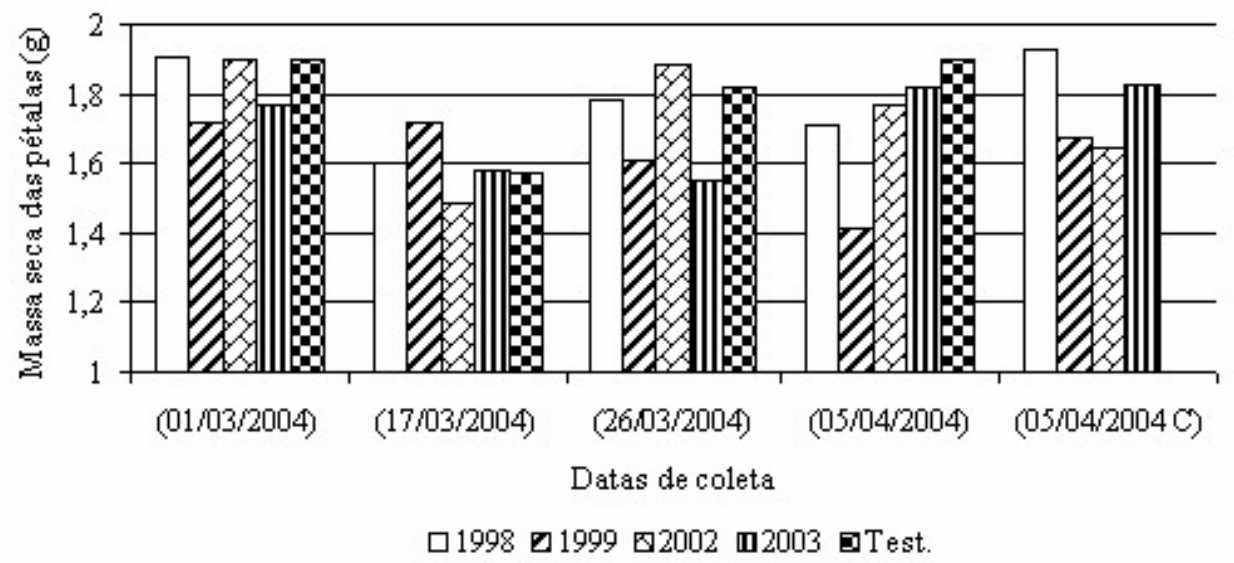

Figura 5 - Valores médios, nas datas de coleta, para a massa seca das pétalas (g) nos diversos tratamentos estudados. A última coluna à direita refere-se aos dados das plantas que foram podadas no início do tratamento.

Tabela 5 - Valores médios de massa seca das pétalas do botão floral (g), nas diversas datas de coleta e nos diversos tratamentos estudados.

\begin{tabular}{cccccc}
\hline Tratamentos & $1 / 3 / 2004$ & $17 / 3 / 2004$ & $26 / 3 / 2004$ & $5 / 4 / 2004$ & $05 / 04 / 04$ Corte \\
\hline 1998 & $1,906 \mathrm{a}$ & $1,600^{\mathrm{a}}$ & $1,783 \mathrm{ab}$ & $1,708 \mathrm{ab}$ & $1,926^{\mathrm{a}}$ \\
1999 & $1,717 \mathrm{a}$ & $1,715^{\mathrm{a}}$ & $1,609 \mathrm{ab}$ & $1,411 \mathrm{~b}$ & $1,675^{\mathrm{a}}$ \\
2002 & $1,902 \mathrm{a}$ & $1,482^{\mathrm{a}}$ & $1,881^{\mathrm{a}}$ & $1,767 \mathrm{ab}$ & $1,645^{\mathrm{a}}$ \\
2003 & $1,766 \mathrm{a}$ & $1,578^{\mathrm{a}}$ & $1,549 \mathrm{~b}$ & $1,821 \mathrm{a}$ & $1,826^{\mathrm{a}}$ \\
Test. & $1,896 \mathrm{a}$ & $1,569^{\mathrm{a}}$ & $1,819 \mathrm{ab}$ & $1,902 \mathrm{a}$ & \\
& & & & & \\
DMS & 0,31 & 0,454 & 0,319 & 0,356 & 0,28 \\
C.V. $(\%)$ & 14,92 & 24,8 & 16,02 & 17,96 & 16,57 \\
Média Geral & 1,827 & 1,589 & 1,728 & 1,722 & 1,768 \\
I.C. $(1-0,05)$ & 0,07 & 0,1 & 0,077 & 0,089 & 0,08 \\
\hline
\end{tabular}

Letras diferentes em uma mesma coluna indicam diferença significativa a 0,05 de significância, para o teste de Tukey.

\section{AGRADECIMENTOS}

ÀCAPES, pela bolsa de doutorado no período de 02/2003 a 02/2005; à Ginegar, pelo filme plástico com características próprias para o cultivo da rosa; ao Sr. Guilherme Reijers, produtor que cedeu o local para a realização do experimento e as rosas para a análise de produção; à funcionária Rosa Helena Aguiar, pela parte laboratorial.

\section{REFERÊNCIAS BIBLIOGRÁFICAS}

BREDMOSE, N. Chronology of three physiological development phases of singlestmmed rose (Rosa hybrida L.) plants in response to increment in ligth quantum integral. Scientica Horticulturae, v. 69, p. 107115, 1997.

\section{CASARINI, E. Doses de N e K aplicados via} fertirrigação na cultura da roseira (Rosa sp.) em ambiente protegido. 2004. 102 p. Dissertação (Mestrado em Irrigação) - Escola Superior de Agricultura de Luiz de Queiroz, Piracicaba, 2004.

COSTA, E. Avaliação da produção de alface em função dos parâmetros climáticos em casas de vegetação com sistema hidropônico nos períodos de outono e inverno. 2001. 144 p. Dissertação (Mestrado em Engenharia Agrícola) Universidade Estadual de Campinas, Campinas, 2001.

CUNHA, A. R.; ESCOBEDO, J. F.; KLOSOWSKI, E. S. Balanço de energia em pimenteiro sob cultivo protegido e a campo. Revista Brasileira de Agrometeorologia, Santa Maria, v. 9, n. 2, p. 156-167, 2001. 
FURLAN, R. A.; FOLEGATTI, M. V. Distribuição vertical e horizontal de temperaturas do ar em ambientes protegidos. Revista Brasileira de Engenharia Agrícola e Ambiental, Campina Grande, v. 6, n. 1, p. 93-100, 2002.

MOE, R. Factors affecting flower abortion and malformation in Roses. Physiology Plant, Washington, v. 24, p. 291-300, 1971

MORANDI, M. A. Gliocladium roseum com agente de biocontrole de Botrytis cinerea em roseiras cultivadas em casa de vegetação. 1997. 60 f. Dissertação (Mestrado em Agronomia) - Universidade Federal de Viçosa, Viçosa, 1997.
PEREIRA, E. R. Cultivo da rúcula e do rabanete sob túneis baixos cobertos com plástico com diferentes níveis de perfuração. 2002. 113 p. Dissertação (Mestrado em Agronomia) - Escola Superior de Agricultura "Luiz de Queiroz", Piracicaba, 2002.

ROCHA, P. K. Desenvolvimento de bromélias em ambientes protegidos com diferentes alturas e níveis de sombreamento. 2002. 90 p. Dissertação (Mestrado em Agronomia) - Escola Superior de Agricultura "Luiz de Queiroz", Piracicaba, 2002

RODRIGUES, E. J. R. Técnicas de cultivo e manejo de roseira em sistemas de cultivo sem solo. 1999. 84 f. Tese (Doutorado em Irrigação e Drenagem) - Escola Superior de Agricultura "Luiz de Queiroz", Piracicaba, 1999. 